\title{
Local Students at University: Narrative Descriptions of Lived Experiences
}

\author{
Lisa Johnson and Nila Wiese \\ University of Puget Sound, United States
}

\begin{abstract}
'Local students' attend college or university in the same city where they attended high school. Local students' selfnarratives suggest that their 'identity or sense of self' and 'sense of belonging or connection with others' may hinder their academic success. This study gathered data from focus groups and surveys of local and non-local students of a private, national liberal arts college concerning their lived experiences as local students at university. This data describes local students' self-narratives about 'identity or sense of self' and 'sense of belonging or connection with others.' The beliefs and experiences reflected by these self-narratives may suggest unique challenges that affect local students' university outcomes. With awareness of these experiences and beliefs, institutions of higher education could tailor programs to benefit local students to improve their sense of well-being, which may improve retention and academic success.
\end{abstract}

Keywords: Local students; retention; academic success; sense of self; belonging.

\section{Introduction}

Students who enroll in institutions of higher education near to their high schools, or near to their homes where they lived during their senior year of high school, experience poorer outcomes in postsecondary educational pursuits as compared to their peers who enroll in schools at greater distances (González Canché, 2018; Klasik et al., 2018). Findings may not be predictive for a best course of action for any specific individual student (Klasik et al.), but, overall, there is a greater likelihood for this group of students to experience poorer academic outcomes. Nevertheless, because students and their families may make decisions about college or university enrollment without complete information about how choice of school location may affect likelihood of outcomes, some students may prefer to enroll in colleges or universities close to home (Klasik et al.), particularly low-income students (Skinner, 2018; Turley, 2009), and those who are socioeconomically disadvantaged (Turley).

Issues that confront local students at universities that may limit or influence their success are multi-faceted and dynamic. The fact that students are local is not likely the only or the determinative factor that may affect their success at university. Local students may also belong to other populations that experience unique challenges to their engagement with and persistence in programs of higher education. Historically underrepresented populations, first-generation students, and other social or economic classes have been extensively studied in educational settings, and those studies reflect wide-ranging focuses (e.g., Baker et al., 2018; Bastedo \& Jaquette, 2011; Engberg, 2012; Hoxby \& Avery, 2012; Klasik et al., 2018; Posselt et al, 2012).

\section{Purpose and Background}

The present study arose from administrative concerns at a private, national liberal arts college located in the Pacific Northwest (hereinafter "the college") concerning observations that local students experienced higher than expected attrition rates from at least 2014-2018. The study's purpose was to gain insight into the lived, narrative experiences of local students to discern 
whether common themes might emerge that could inform an understanding of lived experiences that may have led to, or eventually lead to, pre-graduation departures. The college is in a medium-size city, and most of its students are undergraduate residential students. In fall 2018, the student body consisted of approximately 2400 undergraduate and 200 graduate students. Out-of-state students comprised approximately $74 \%$ of its student body from 46 states and territories, and eight countries. There were 83 local students in attendance during fall 2018.

In fall 2014, the college launched a program to support local students (referred to as the XPS Initiative). The XPS Initiative provides financial support for up to 30 local students per year who have graduated from the local public school system. The financial support is determined by each student's annual unmet demonstrated financial need as documented on the Free Application for Federal Student Aid form based on the cost of attendance. The cost of attendance includes tuition, room, board, fees, and additional costs. Objectively, the XPS Initiative program should remove any financial burden for XPS Initiative students to complete their education. Despite this financial support, XPS Initiative students have lower retention rates, and they have not performed as well academically as their peers. Not all local students at the college are XPS Initiative students. Local students who attend the college, but who are not XPS Initiative students, also experience these academic challenges. Equally troublesome is that some local students who were thriving academically while at the college chose to leave before graduating. By fall 2018, the college had admitted 110 XPS Initiative students. Individual students in the XPS Initiative do not share common defining characteristics other than having come from the local public school system. They represented many different backgrounds, including some from historically underrepresented populations and first-generation students. However, XPS Initiative students may also be children of faculty or staff, and they may be members of none of these groups.

Two themes, which had been developed from the existing literature, were identified from the data collected: identity or sense of self and sense of belonging or connection with others. While these themes have been addressed in the existing literature in different contexts, they have not been considered from narratives of local students in four-year private liberal arts colleges in the United States. This focus provides an important contribution to understanding the overall landscape of academic outcomes by providing a framework to describe challenges experienced by local students in the United States from their own perspectives.

Lack of research attention to this distinct population in the United States may exacerbate the academic difficulties experienced by local students, because programs that could exist to support them do not yet exist; or, where such programs exist, they may not be informed by research. This study begins to fill that gap. It expands the body of knowledge concerning local students and the poorer academic outcomes that they may experience relative to their peers by presenting their narratives of identity or sense of self, and sense of belonging or connection with others and linking those narratives to themes suggested in non-U.S. studies. The present study reflects that "the complexity of belonging warrants rich narratives and experiences of students to articulate how it is experienced and understood" (Guyotte et al., 2021, p. 545).

\section{Definitions}

The present study defines local students as current and former students who attend or have attended university in the same city in which they attended high school. This definition is similar to the focus of prior works that have been interested in questions related to students who attend college or university near to their high school. For example, González Canché (2018) uses "nearby college enrollment" to denote enrollment in any of the five institutions that are nearest to the student's residential zip code while attending high school (p. 896). Jacob et al. (2018) has defined the distance variable between a student's home and institutions of higher education as the distance between the zip codes of the student's high school and the institution of higher education. Turley (2009) focuses on "college proximity," defining it differently for urban and rural areas (12-mile radius versus 24-mile radius, respectively), and using it to indicate commuting distance from a student's residence during high school senior year.

This study categorizes identity or sense of self, and sense of belonging or connection with others to encompass observed themes expressed by local students that may present challenges to their academic success at university. We adopt YuvalDavis's notion of identity as "a specific kind of narrative in which people tell themselves and others who they are, who they are not and who/how they would like to/should be" (2010, p. 279). A sense of self is a "process of self-conceptualization," dynamic and changeable in nature (Nizzi, 2018, p. 7). In conjunction, identity or sense of self permits capture of either selfnarrative or self-conceptualization, or both. 
Likewise, the two terms, sense of belonging and connection with others, have been grouped as a single category. These may co-exist in or be experienced by any individual student, but each also may be subjectively experienced independently from the other. Both terms have at their core a particular type of relatedness to others, including to communities and to individuals within those communities. We favor Goodenow and Grady's (1993) understanding of a sense of belonging, but enhance it with Yuval-Davis's (2006) and Guyotte et al.'s (2021) critical insights. For students, a sense of belonging may be understood as "the extent to which they feel personally accepted, respected, included, and supported by others" (Goodenow \& Grady, p. 61). Belonging is also "about emotional attachment, about feeling 'at home"” and, as identified by Ignatieff (as cited by YuvalDavis, 2006), is "about feeling 'safe"” (Yuval-Davis, 2006, p. 197). Belonging may not be permanently achievable due to the constancy of change in people, places, ideologies, politics, and time; therefore a sense of belonging is shiftable, impermanent, and relationally negotiable (Guyotte et al.). Belonging is "an essential need, an active process of forming connections, vital to the full participation and inclusion of all young people” (Picton \& Banfield, 2019, p. 117). Students' connections to others are changeable, transitional, relational, and dynamic (Guyotte et al.). Taken together, a sense of belonging or a connection with others includes expressions of a particular type of relatedness to others or place that connote meaningful, high quality feelings of a close, personal connection or being at home.

\section{Research Questions}

The original research question was: "What are the attributes of local students?" As the project progressed, we observed that local students' narratives about their lived experiences contained rich content about their beliefs and experiences concerning their status as college students near to their high school environment. Therefore, we refined our research question. Rather than categorizing specific attributes, we identified themes in the student narratives; these themes were developed in conjunction with the existing literature. The two themes were identity or sense of self, and sense of belonging or connection to others. Once data was collected and these themes were identified, we attempted to answer a refined research question: "How do local students express their lived experience at university in terms of identity or sense of self, or sense of belonging or connection to others that may suggest challenges for their academic outcomes?"

\section{Limitations}

Social, cultural, or economic factors that may be explanatory or predictive for local students' success were not identified, described or addressed. The scope was limited to current and former undergraduate students who were attending a private, residential four-year college during fall 2018 or had attended between 2014-2018 but left before graduating. Descriptive categories may be generalizable where local students comprise a minority population in private, residential four-year colleges or universities in the United States. Observed descriptive themes expressed by local students have not been compared against low-income, first-generation, or historically underrepresented groups. Other themes may exist that have not been described by this study. This study was also limited by the small number of participants in focus groups and surveys.

\section{Previous Studies and Review of the Literature}

The purpose of this literature review is twofold. First, it exists to demonstrate that the academic outcomes of local students in the United States have received some attention, but that existing U.S. studies are largely concerned with interpretation of quantitative data sets, rather than qualitative thematic analyses. Second, it examines the themes that have emerged in qualitative works focused on local students; these works were drawn from data from various sites in the UK, Northern Ireland, and Australia, and they suggest themes of identity or sense of self and sense of belonging or connection with others. The themes in the present study were derived from these qualitative non-U.S. studies, and they are summarized in Table 1. 
Table 1

Themes Expressed in the Narratives of Local Students (LS), Suggested by the Literature

\begin{tabular}{|c|c|}
\hline $\begin{array}{l}\text { Theme 1: } \\
\text { Identity or sense of self }\end{array}$ & $\begin{array}{l}\text { Theme 2: } \\
\text { Sense of belonging or connection with others }\end{array}$ \\
\hline LS may not demonstrate 'student' lifestyle & LS believe they no longer 'fit in' locally \\
\hline Compelled 'fit' to 'be a student' results in dissonance & $\begin{array}{l}\text { LS may believe that they are 'different' in ways that matter from school } \\
\text { peers }\end{array}$ \\
\hline Competing understandings of self generates suffering & LS may feel rejected or isolated in local and/or university spaces \\
\hline Conflicting, split, or dual identities & LS may seem like cultural 'strangers' at university \\
\hline \multirow{6}{*}{$\begin{array}{l}\text { LS may be perceived as lacking independence in comparison } \\
\text { to institutional peers }\end{array}$} & LS may employ distancing techniques \\
\hline & LS may feel 'classed' at university \\
\hline & LS may have a sense of 'missing out' if they do not live on campus \\
\hline & $\begin{array}{l}\text { LS may feel unable to integrate both local and university spaces and } \\
\text { may live separate 'lives' }\end{array}$ \\
\hline & $\begin{array}{l}\text { LS may already have local friends; may not forge connections with } \\
\text { university peers }\end{array}$ \\
\hline & $\begin{array}{l}\text { LS may perceive university as a barrier to forming new friendships } \\
\text { with non-LS }\end{array}$ \\
\hline
\end{tabular}

\section{Studies Related to Geographic Nearness to Students' High School or High School Residence}

Some studies have provided insight into local students' challenges in postsecondary education. Of interest are those that have examined challenges associated with geographic proximity to students' high school residences and their college choices that have provided explanatory frameworks for poorer academic outcomes. González Canché (2018) builds upon the geographic labor mismatch framework to understand mismatching in postsecondary education, and to explain findings that students who enroll in nearby colleges suffer poorer outcomes than those who enroll in a college more distant than the five nearest colleges to the student's home at time of application. Students who enroll in nearby colleges or universities are significantly less likely to attain a four-year degree and, compared to their counterparts who traveled greater distance for their post-secondary educations, they experienced significant decreases in their salaries (at least in the studied short-term) (González Canché). Both decrease in salary and lower student-loan debt may reflect that students who enroll in nearby colleges may not have attained their four-year degrees (González Canché). In the academic setting, mismatches can occur when students make decisions to attend university or college nearby, despite being academically qualified to attend a more selective institution (Ovink et al, 2018). Mismatching may occur for reasons that include a lack of understanding of the benefits of attending the most selective college that the student may be admitted to (González Canché), financial concerns or lack of resources to attend school at a distance, cultural demands or preferences, or the necessity to attend to family (Ovink et al.).

Students undermatch when they attend a less selective university than their academic preparation, consequently missing out on many benefits, and suffer lower graduation rates and poorer employment outcomes (Klasik et al., 2018; Ovink et al., 2018). Klasik et al. was concerned with student applications to and enrollments in institutions of higher education in students' "commuting zones" (p. 5). They examined "match deserts", in which students' homeplaces did not have an 'academic match' within their commuting zone. They found that students who lived in match deserts were less likely to apply to a match school outside of their commuting zone or to enroll in one (p. 12). This likelihood increased for Hispanic students, for first-generation students, and for students from low-income families (Klasik et al.). Such a result may be due to the difficult calculus involved in determining a match; that is, if a "reasonable-looking, non-academically-matched institution[...] nearby" exists, but it is not an academic match, there may be difficulties in assessing the "costs and benefits of not attending an academic match," a particular hazard for students from non-privileged backgrounds (Klasik et al., pp. 17-18). Ovink et al. showed that undermatching is a problem for low-income students. While there may be an actual geographic mismatch between selective college recruitment and high schools, there may also be assumptions of cultural mismatch on the part of the students regarding 
their ability to fit into selective institutions' cultures. Desires to save money and live near or at home can result in undermatching (Ovink et al.).

The present study recognizes that students sometimes make enrollment choices based upon non-academic factors. Students will continue to enroll in local schools and may continue to suffer poorer educational outcomes as a group. Not all geographically proximate colleges or universities are undermatches for local students. The present work addresses the lived experiences of local students who are already enrolled in a geographically proximate college to their high school residences. Therefore, its goal differs from that of these researchers.

\section{Studies Related to Themes}

\section{Theme 1: Identity or Sense of Self}

The term "student" implies a certain lifestyle or experience, often used to refer to a specific typology of "white, middle class, and mobile young people" (Holdsworth, 2009a, p. 228). However, local students may not be geographically mobile; consequently, they may not fit this typified lifestyle or experience. Dissonance may exist between local students' lived experiences and the typology of student that may be imposed upon them.

Identity related to student status may alter local students' local identities. Once they become students, they "risk...changing into a different person, as they move into a potentially very different world" (Patiniotis \& Holdsworth, 2005, p. 91). Local students may be "strangers in Paradise," culturally speaking (Reay et al., 2009). Some see themselves with split identities, as they view attending school as part of their day or working identity without taking on a student identity (Christie et al., 2005). Abrahams and Ingram (2013) observed that local students may experience complex, nuanced challenges associated with their status as local students, as they negotiate their home and university spaces. Local students may bend their identities to fit a particular meaning of being a student, which may create challenges (Abrahams \& Ingram, p. 1, para. 1.2). Feeling compelled to fit can lead to discord among local students, though some may also reject such notions about studenthood (i.e. that there is only "one authentic" model to being 'a student') (Christie et al., 2005, pp. 5-6).

Students who live at home may not be viewed as independent, since that trait is associated with geographic mobility (Abrahams \& Ingram, 2013, p. 2, para. 1.4). However, assumptions about geographic mobility as necessary to show one's independence have been disputed (see e.g., Christie et al., 2005; Holdsworth, 2009a). Equating independence with geographic distance may be fallacious, because many non-local students are more dependent financially than their local peers who have other obligations reflecting independence (Abrahams \& Ingram, p. 2, para. 1.4):

\footnotetext{
Mobility is not a necessary condition of negotiating transitions to adulthood, particularly for learning about responsibilities, though it is often assumed to be the case. Rather in celebrating students' mobility we are valorising a particular model of transition to adulthood which focuses on separation, self-reliance, and responsibility for the self, rather than one based on interdependencies, mutual support, and responsibility for others. (Holdsworth, 2009b, p. 1861)
}

The narrative that local students tell themselves and others about themselves may differ from the student typology. Since identity is a narrative people tell to convey "who they are, and who they are not" (Yuval-Davis, 2010, p. 279), when competing narratives exist internally or are imposed by others, the "process of self-conceptualization" that forms one's 'sense of self' may become quite fractured (Nizzi, 2018, p. 7).

\section{Theme 2: Sense of Belonging or Connections with Others}

Local students have a strong sense of being between two worlds, taking on a dual identity, forced to navigate family and university life without fully belonging to either (Holdsworth, 2009a). Local students who live off-campus may be perceived as "missing out" (Holdsworth, 2006, p. 512). Local students may experience relational challenges that affect sense of belonging or connection with others, though others have questioned whether a sense of belonging is truly experienced as a problem (e.g., Christie et al., 2005, p. 11).

We discuss habitus because it appears in the existing qualitative literature concerning local students. Though application of Bourdieu's theory of habitus is "almost de rigueur to unpacking the experiences of 'non-traditional' students in higher education" (Patiniotis \& Holdsworth, 2005, p. 84), we engage it merely as an expedient vehicle for understanding existing literature that has been essential for the development of our themes. Scholarship surrounding the concept of habitus is complex, and disputes exist about its appropriate scope and application (e.g., Burke et al., 2013), and the corpus of habitus scholarship is beyond our scope. In sum, habitus is a systemic understanding of one's world developed through socialization and 
internalization of norms, embodying "thoughts, attitudes, and ways of understanding that are constantly constructed within the social world" (Pretorius \& Macaulay, 2021, p. 627). Habitus is dynamic and flexible, encompassing both individual and collective concepts (Burke et al., p. 179) or individuals and groups (Pretorius \& Macaulay).

Abrahams and Ingram's (2013) found that local students may experience discordance between their embodied 'local person' with that of the university environment (p. 3, para. 2.2). They might experience a "habitus tug", which occurs when two conflicting fields cause one's sense of habitus to become destabilized (Ingram, 2011, p. 290). Attempts to identify with both local and university fields can result in great "emotional labour" (Reay, 2002, p. 222 and footnote 1) and "generat[e] suffering" (Bourdeiu, 2000, p. 160, cited in Abrahams \& Ingram, p. 3, para. 2.3).

For 'working class' students, the local and university habitus fields can be misaligned and students can experience "conflicting identities" (Abrahams \& Ingram, 2013, p. 3; Ward, 2019, p. 168). When students do not fit either 'world,' they may feel rejected or isolated (Holdsworth, 2009a). They might rectify this split by "distancing from the university field," "distancing from the local field," and/or "adapting to both fields" (Abrahams \& Ingram, pp. 3-4). Students who employ a distancing strategy may not be seeking an "all-encompassing" university experience but, rather, a functional relationship with the university to earn a degree (Abrahams \& Ingram, p. 2, para. 1.6). Local students are aware of feeling different and not "quite fit[ting] in the university field" (Abraham \& Ingram, p. 4). Among those who employed a "distancing from the university field" strategy, some developed: a belief that they could not successfully integrate into both fields; a 'study and leave' strategy; a belief that they could not be themselves at university; and a focus on coming to school "for a degree, rather than social life" (Abrahams \& Ingram, pp. 5-8). Those who employed a 'distancing from the local field' strategy, in time, moved towards others with higher education; changed in speech and behavior as a consequence of attending university; or, sensed "not fitting in as well" in their original (local) field (Abrahams \& Ingram, p. 9). Among those who employed an 'adapting to both fields' strategy, some recognized that they were living 'two lives' but had committed to keeping them separate (Abrahams \& Ingram). Relatedly, being classed based on how one communicates (e.g., use of accent or slang) can cause local students to feel that they do not fit in at university, and may lead to self-consciousness, humiliation, and a sense of devaluation (Addison \& Mountford, 2015).

McKenzie and Baldassar (2017) wanted to learn why local students do not form friendships with international students. At their study site, approximately $71 \%$ of the students were local and approximately $20 \%$ were international (McKenzie \& Baldassar). They found local students have entrenched friendships in local bubbles; space and structure provided by the university for certain purposes were barriers to natural friendships developing because they excluded local students (e.g., the international clubs); and events were barriers (e.g., different orientation programs for international and local students) (McKenzie \& Baldassar).

Challenges to local students' sense of belonging or a connection with others is a pervasive theme in the literature. When students perceive themselves classed, or between two worlds but not fully in either, or as not fitting in for whatever reason, the relational qualities that are necessary to experience a sense of belonging or connection with others are jeopardized. If relationships are perceived as less-meaningful, less-close, less-respectful, less-accepted, less-inclusive, or less-supportive, or any combination of those or other deficiencies, then a sense of belonging or connection with others may be diminished.

\section{Methodology}

The researchers followed customary methodological procedures for collecting focus group and survey data (e.g., human subjects' approval of research protocol, informed consent, confidentiality of subjects). Focus group participants benefited by being offered a free lunch, an opportunity to interact with peers, the potential to learn from each other's experiences, and the opportunity to shape and share their narratives about their lived experiences.

Local student research subjects were composed of both local students (including XPS Initiative students) and non-local students. Non-local students were randomly selected from the college email database. The total local student population size during fall 2018 was 83 students (79 then-current students and four who had matriculated during 2014-2018 but left before graduating). All members of this group were invited to participate via email. The criteria for local student subjects were that, at the time of the study, they must be at least 18 years of age; be local students at the college (i.e., students who attended high schools belonging to the local public school system at least three years prior to matriculating at the college); and, must be either currently enrolled at the college, or previously enrolled at the college during the last four years, but had left prior to 
graduating. The criteria for non-local student subjects were that, at the time of the study, they must be at least 18 years of age and be currently enrolled at the college.

Both researchers were present for all focus groups, which were conducted during one-hour time slots on October 22 (7 students) and October 31 (6 students), 2018. The first focus group consisted of local students; the second consisted of nonlocal students. For all focus groups, there was good representation of students from all academic years and a variety of majors. Subjects were asked a series of guiding, semi-structured questions, and their responses were audio-recorded and transcribed by computer. Focus group subjects were encouraged to participate in the discussion, but were free to participate or not participate. Researchers interrupted only when discussion strayed off-topic, to probe an existing line of inquiry, or to ask follow-up questions. We invited electronic survey participation via email, which was disseminated to potential subjects meeting the local student subject criteria. Sixteen surveys from current local students and six from former local students were completed: $27 \%$ first year, $33 \%$ sophomores, $27 \%$ juniors, and $13 \%$ seniors, reflecting a $26.5 \%$ survey response rate. Surveys consisted of both closed- and open-ended questions.

In the focus groups and surveys of local students, participants were asked to reflect upon their experiences as local students, and to identify the major advantages and disadvantages (i.e., challenges and pressures) derived from their status as local students. Students were asked to assess university programs and resources they found helpful for achieving social integration and academic success. Participants in the non-local student focus group were asked about their perceptions of and interactions with local students.

Thematic analysis reflects a flexible foundational methodology in qualitative work, such as the present study, to identify themes in data (Braun \& Clarke, 2006). Thematic analysis was appropriate for use in the present study, which "reports experiences, meanings and reality of participants" (Braun \& Clarke, p. 80). Responses to all focus groups and surveys were analyzed for latent themes, rather than merely semantically (Braun \& Clark), and to identify themes representative of participants' narratives that may present academic challenges. Specifically, we attempted to "identify or examine the underlying ideas, assumptions, and conceptualizations/and ideologies/ that are theorized as shaping or informing the semantic content of the data" (Braun \& Clarke, p. 84). This process is necessarily "interpretative work" that is "not just description, but ... already theorized" (Braun \& Clark, p. 84).

We identified a set of preliminary codes used to categorize participants' responses into the two themes of interest (Braun \& Clarke, 2006, p. 80): identity or sense of self, and sense of belonging or connection with others. The codes and themes were developed from extant literature and capture important issues from the data in relation to our research question, without necessarily reflecting prevalence (Braun \& Clarke). Here are examples of the initial coding used: (a) For identity or sense of self we tagged words and phrases such as identity, dual identity, conflicting identity, independence, local, and self-identifying demographic characteristics related to race/ethnicity, social class, and income. (b) For sense of belonging or connections with others we tagged words and phrases such as fit, belonging, inclusion, isolation, rejection, friends, campus life, home, relationships, socializing, and community.

Though our original research question sought to identify attributes of local students, in so doing, we identified rich, descriptive, subjective content in the narratives of local students that was thematically analyzed. Thematic analysis permits such a departure from original plans, and it recognizes that though "projects are guided by research questions, these may also be refined as a project progress" (Braun \& Clark, 2006, p. 85). Moreover, original research questions themselves provide quite poor themes (Braun \& Clark). We identified themes during the research project and analyzed their expressions in a data-driven, inductive thematic analysis; responses were not coded for a specific research question; instead, the "research question... [evolved] through the coding process" (Braun \& Clark, p. 84).

\section{Results}

Descriptive narratives from focus groups and survey responses were coded using a preliminary list of words and phrases, and collated into two categories, Theme 1 and Theme 2.

\section{Theme 1: Identity or Sense of Self}

Local students believe that peer perceptions of them are linked to their peers' erroneous and negative perceptions of the city where the college is located. Local students opine that these misperceptions are attributable to lack of familiarity and knowledge about the city. Nevertheless, these perceptions negatively impacted local students: they felt uncomfortable on 
campus and experienced difficulties fitting in and participating in campus life. Some discussed the challenge of defining and living their identities due to stigmas they faced on a variety of fronts (e.g., being ghetto or 'local', low income, from a particular racial group, first-generation student, etc.). Some additional comments included: "Weird how much of a bubble [our college] is"; "so many people do not leave campus, or go any further than a mile from campus;" "[The city] is seen as dirty, dangerous." Negative city perceptions were frustrating because local students felt that the city "has everything" and non-local students just needed to "leave campus and explore," or "develop a thicker skin and try things out." The divergent views held by local students (who saw their city in a positive light) and by non-local students (who saw the city in a negative light) led to local students' conflicting identities:

People from [the city] do not have the best reputation within the student community and vice versa. Sometimes it felt like I didn't belong anywhere. People from my [high school] thought I was just another rich spoiled [college] kid and people from [the college] thought I was some low-life [local] guy.

Local students saw their locality as both positive and negative. On the one hand, they felt that being local had many advantages. They could switch between home and campus, depending on their needs, seeking seclusion from family on campus or going home when needing emotional support or access to resources (e.g., laundry, a home-cooked meal, visiting pets). Also, they have a wider world in which to operate vis-a-vis non-local students who limit themselves to the 'campus bubble.' Additionally, they saw themselves as city experts, taking pride and satisfaction in being able to guide their peers around town, and acting as tourist guides as they shared their intimate knowledge of the city with classmates. They also saw access to jobs in town as a positive. On the other hand, living in their hometown has its drawbacks. Pressures from their home life can be disruptive both in terms of the time that attending to these pressures requires (e.g., choir practices at church), and in terms of the emotional burden. Some students' families depend on them for everyday tasks (e.g., translation, paying bills, helping with siblings). Local students were adding new dimensions to their existing identities (e.g., experts, tourist guides), while trying to downplay or distance themselves from other elements of their identities (e.g., son/daughter, sibling, church member).

Many local students perceived differences in income and social status, and expressed how different their peers were in terms of their financial situations. One said that a classmate was able to pay tuition out of pocket while both her parents' incomes were not enough to cover one year of tuition. Others expressed surprise at how classmates could just "call home" to ask for money, or how "clueless" friends were about completing financial aid forms or paying taxes. A few stated their "rich classmates" did not care about having money. Another noted that they did not know whether to feel guilty, embarrassed or proud of their small tuition bill (due to the financial aid received through the XPS Initiative scholarship). Ability to study abroad was an area where income and social class affected local students' sense of self. Some said they felt pressure to study abroad from faculty and peers, and that their "perceived reluctance" was equated with being "close minded" and unwilling to "explore the world," instead of financial inability.

Perceptions about differences in socio-economic status were also linked to students' own perceptions of independence. Nonlocal students can be perceived as independent because of their geographic mobility (i.e., moving away from home to attend college), but they can also be perceived as financially dependent (i.e., relying on their families for tuition and living expenses). Local students may be dependent on their families' support but may perceive this dependence as a benefit of being local ("If I need anything, my parents are right there." "I got sick and could go home."). However, their perceived lack of money may make them feel as less independent: "The income level, and consequently personalities, of the other students on campus are a drastic shift from high school and make it feel harder to be mature and independent." At the same time, local students' more intimate knowledge of the city and their family responsibilities may increase their own sense of maturity and independence (e.g., knowing where to go for good food, helping parents with completing their tax forms).

Local students seemed to struggle defining their identity more so than non-local students, especially regarding having a dual identity. Several discussed not being able to disconnect their home life from their university life and feeling pulled from home regularly, which amplified their transition stress to university. In some cases, students had a strong sense of duty and responsibility towards helping their families (e.g., one first-generation student stated her only goal in completing her education was to be able to help her family). Many students worked off-campus and were consequently unable to participate in campus activities and events. As a result, they did not feel like they have a typical student's college experience. Many expressed that they would like to be more involved but simply could not, due to existing off-campus responsibilities. Finally, some students expressed they would have liked to "go away for college" to find themselves, but that this had not been an option for them. 


\section{Theme 2: Sense of Belonging or Connections with Others}

Local students, as compared to non-local students, seemed to question more the similarities and differences between the college campus and the city. They noted that the college "is not [the city]" and that campus and home felt like "two completely different atmospheres." Several students explained, for example, that the north part of town [where the college is located] and the south and east parts of town [typically lower-income, more ethnically diverse] are very different, and that many of the social issues they have encountered in their neighborhoods and high schools are not present on campus. Some students shared how at their local high schools, "each corner of the globe was represented," while on campus, there was far less diversity. That some students on campus are so "totally unaware or uneducated" about basic differences between people made it hard for local students to assimilate into the campus environment. This disconnect between the perceived experiences of local and nonlocal students increases local students' feelings of loneliness, otherness, and inadequacy.

The literature suggests that students who have a strong sense of belonging would feel an emotional attachment to the college, and feel more accepted, included, and comfortable. Local students in our study expressed a lower sense of comfort and ease in connecting to the college and making new friends. Students noted: "[it was difficult] not making many friends freshman year. I was spending every weekend with friends from high school"; "I have had difficulty feeling like I belong on campus"; and, "Being a local student is very hard on this campus due to not feeling comfortable. This...causes many of us to spend all of the time we can at home..."

Feeling safe and supported also adds to students' sense of belonging. Local students expressed feeling fearful and anxious, and not always understood or supported. Many were concerned about being able to afford basics (e.g., housing, books). One mentioned being "terrified of junior year when there will be no support from the college for housing." The high cost of books, especially, was mentioned as a financial barrier by many students. Some said they had had to drop classes because they could not afford the books, and that in some cases, instructors did not offer options for accessing the required reading materials. Other students said they felt either intimidated or embarrassed asking for "assistance for books" and this made them reluctant to approach professors about it, opting to drop courses instead. Being able to fully participate in campus life is highly dependent on financial resources. For example, studying abroad was not an option for many, particularly for those who could not afford to "not work" for an extended period. Some local students felt misunderstood rather than supported when others perceived them as "close minded" for not pursuing study abroad opportunities.

Several local students indicated that the preparation they had received in the local high schools was insufficient, and that they did not feel prepared for the rigors of college. Some students admitted that being a "good student in high school" did not guarantee success in college. Those students noted not being prepared for that reality. A perceived or actual inability to "meet academic expectations" led to other challenges. Some indicated feeling inadequate or that they did not belong. Others shared that they had friends who were dropping out or had begun to take drugs to deal with the pressures. This mismatch between a student's perceived and actual levels of preparation can impact a student's sense of self (an impostor syndrome type-situation), which could, in turn, exacerbate a student's lack of self-confidence and fear of failure.

Asking for help or support was acknowledged as a significant barrier, even if students knew resources existed; this was especially the case for first- and second-year students. For example, many said they were not aware of tutoring services or hours at the college's learning center. Some said they had "tried the center" but had not found the feedback received specific enough to be helpful (i.e., writing tutors assumed they knew the basics of good writing), thus choosing not to return. Finally, students who worked off-campus were less able to access academic resources because of scheduling conflicts. Some students expressed dissatisfaction with what they considered inadequate guidance to navigate college life (e.g., advising related to majors and minors, specific curricular needs, or careers after college).

Faced with opposite pulling forces (local home and college), and with incongruent cultures and environments (local community vs. the college campus), local students seemed to cope by adopting one of three strategies: distancing from the university field, distancing from the local field, or adapting to both fields. This is in line with existing literature. 1) Distancing from the university field:

The culture at [college] is very different from what I experience from actually being in [city] growing up. I also have to go home a lot to take care of my parents. It also can be very boring here because [the college] does not offer many activities [compared to what the city offers]. 
2) Distancing from the local field: "It's hard for [my local friends] to understand that even though I'm still around that I don't have time to hangout." 3) Adapting to both fields: "Being close to home so if I need/want to see my family I can, but I still feel like I'm in a new environment meeting new people..."; and, "Although having family nearby can be a burden (freshman year...they somewhat treated me like I was not busy with school and work), for me, ...many of my problems are [helped] by being local and having so much family nearby."

A summary of findings is presented in Table 2.

Table 2

Themes Expressed in the Narratives of Local Students (LS), Suggested by Focus Groups \& Surveys

\section{Description of findings}

\section{Impact on academic success}

Theme 1: Identity or sense of self

Self-Perceptions: LS saw themselves as 'different' from other students based on their lived experiences and their status as 'locals.'

Peer-Perceptions: LS expressed feeling that non-LS seemed to see them as 'inferior.'

LS indicated that their local family and friends do not understand the demands of college.
The 'pull' effects of the local persona are likely to have both negative and positive impacts on students' academic success:

Negative: (1) Time away from campus leaves LS less time to study and to participate in extra- and co-curricular activities.

(2) Mental and emotional stress especially impactful when LS are pulled away from school due to home situations.

Positive: (1) Local family and friends may provide emotional and practical support.

(2) Campus provides LS a 'safe space' to try to 'find themselves'; provides opportunity to challenge their beliefs, away from criticism or rejection from local family and friends.

(3) The opportunity to 'act as experts on their city' gave local students a sense of pride. This opportunity, if leveraged, can have a positive impact on students' self-esteem and sense of belonging.

Theme 2: Sense of belonging or connections with others

LS may experience feelings of loneliness, otherness, and inadequacy, especially where demographic differences between college 'bubble' and surrounding city are pronounced (national, private, majority white student population at college versus ethnically and socio-economically diverse city).

LS expressed a sense of pride in 'belonging' to their local community, and saw an opportunity to enrich their classmates' college experiences by helping them learn more about the city.
Feelings of isolation, otherness, and inadequacy can have negative effects on student's mental and emotional health, which in turn can have a negative impact on their academic success.

Finding a campus community or affinity group early in the academic program is essential to LS ability to succeed academically.

LS isolation can be relieved by connections to local family and friends, though such connections may interfere with academic success. 


\section{Discussion}

The narratives of local students that may reflect challenges to their university success may be generalizable across similar institutions of higher education (e.g., four-year, private) or other institutions, particularly where local students are in the minority. For example, local students often reported distractions attributable to their pre-university lives in the off-campus community, such as from high school friends, church, or family. These distractions are not unique to local students attending the college where the data was gathered. Additionally, local students' perceived necessity to maintain two identities in such situations might also be expected. Isolation, loneliness, and distancing from (or never fully engaging with) the university community are consequences that might be expected in similar situations, regardless of locale. As such, theme 1 and theme 2, and the many expressions of each of those themes captured in the narrative data and found in the literature, might be expected to be generalizable characteristics of local students. These findings, summarized in Table 2, are consistent with the extant literature.

\section{Identity or Sense of Self}

Local students may assume a dual or split identity. These identities correspond to a college persona and a local persona, the latter of which may remain dominant, at least early in the students' college careers. Balancing an existing local identity with the new college persona is a struggle. The college persona may lead to them being seen as outsiders in their local community, while their local persona may result in them being seen as outsiders on campus.

\section{Sense of Belonging or Connections with Others}

Local students feel isolated, othered, and inadequate. The literature mentions that when misalignment between students' local and university environments is significant, students may try to deal with the incongruence by distancing from the university field, distancing from the local field, or adapting to both fields. Both distancing strategies were observed in the present study, though students also seemed willing to adapt to both fields in ways most conducive to their academic success. Adaptation, however, was not painless, as evident from local students' narratives that there were economic and emotional burdens that were completely absent from the non-local students' narratives.

The economic and emotional challenges expressed by some local students suggest negative effects on their academic performance, such as inadequate study time, and inabilities to engage in cocurricular and extracurricular activities, study abroad, or access to learning resources. Nevertheless, no generalization about student success can be inferred from the bare fact of an individual student being a local student. For example, in McKenzie and Baldassar's (2017) work, most students at the university where the study was based were local students, which is a sharp contrast with the college where the present study took place. Where most students on campus are local students, some themes suspected as contributing to academic challenges might not pose any specific problem, such as a sense of fitting in.

\section{Conclusion}

Institutions experiencing higher attrition rates or poorer academic performance by local students should develop specific programs to help these students succeed in their transition to university. Targeting local students' challenges could help this unique population overcome real or perceived barriers that may contribute to poorer academic outcomes. The findings from this study provide a scholarly foundation from which to base additional research and to develop targeted institutional responses. 


\section{References}

Abrahams, J., \& Ingram, N. (2013). The chameleon habitus: Exploring local students' negotiations of multiple fields. Sociological Research Online, 18(4), 1-14. https://doi.org/10.5153/sro.3189

Addison, M., \& Mountford, V. (2015). Talking the talk and fitting in: Troubling the practices of speaking 'what you are worth' in higher education in the UK. Sociological Research Online, 20(2), 1-13. https://doi.org/10.5153/sro.3575

Baker, R., Klasik, D., \& Reardon, S. F. (2018). Race and stratification in college enrollment over time. AERA Open, 4(1). https://doi.org/10.1177/2332858417751896

Bastedo, M. N., \& Jaquette, O. (2011). Running in place: Low-income students and the dynamics of higher education stratification. Educational Evaluation and Policy Analysis, 33(3), 318-339. http://dx.doi.org/10.3102/0162373711406718

Braun, V., \& Clarke, V. (2006). Using thematic analysis in psychology. Qualitative Research in Psychology, 3(2), 77-101. http://dx.doi.org/10.1191/1478088706qp063oa

Burke, C., Emmerich, N., \& Ingram, N. (2013). Well-founded social fictions: A defence of the concepts of institutional and familial habitus. British Journal of Sociology of Education, 34(2), 165-182. http://dx.doi.org/10.1080/01425692.2012.746263

Christie, H., Munro, M., \& Wager, F. (2005). 'Day students' in higher education: Widening access students and successful transitions to university life. International Studies in Sociology of Education, 15(1), 3-29. https://doi.org/10.1080/09620210500200129

Engberg, M. E. (2012). Pervasive inequality in the stratification of four-year college destinations. Equity \& Excellence in Education, 45(4), 575-595. http://dx.doi.org/10.1080/10665684.2012.717486

Goodenow, C., \& Grady, K. (1993). The relationship of school belonging and friends' values to academic motivation among urban adolescent students. The Journal of Experimental Education, 62(1), 60-71. https://doi.org/10.1080/00220973.1993.9943831

González Canché, M. S. (2018). Nearby college enrollment and geographical skills mismatch: (Re)conceptualizing student out-migration in the American higher education system. Journal of Higher Education, 89(6), 892-934. https://doiorg.ezproxy.ups.edu:2443/10.1080/00221546.2018.1442637

Guyotte, K., Flint, M., \& Latopolski, K. (2021). Cartographies of belonging: Mapping nomadic narratives of first-year students. Critical Studies in Education, 62(5), 543-558. http://dx.doi.org/10.1080/17508487.2019.1657160

Holdsworth, C. (2006). 'Don't you think you're missing out, living at home?': Student experiences and residential transitions. The Sociological Review, 54(3). https://doi.org/10.1111/j.1467-954X.2006.00627.x

Holdsworth, C. (2009a). Between two worlds: Local students in higher education and 'scouse'/student identities. Population, Space, and Place, 15, 225-237. https://doi.org/10.1002/psp.511

Holdsworth, C. (2009b). 'Going away to uni': Mobility, modernity, and independence of English higher education students. Environment and Planning A: Economy and Space, 41(8), 1849-1864. http://dx.doi.org/10.1068/a41177

Hoxby, C. M., \& Avery, C. (2012). The missing "one-offs": The hidden supply of high-achieving, low income students (No. w18586). National Bureau of Economic Research. https://www.nber.org/papers/w18586

Ingram, N. (2011). Within school and beyond the gate: The complexities of being educationally successful and working class. Sociology, 45(2), 287-302. https://doi.org/10.1177/0038038510394017

Jacob, B., McCall, B., \& Stange, K. (2018). College as country club. Journal of Labor Economics, 36(2), $309-348$. http://dx.doi.org/10.1086/694654

Klasik, D., Blagg, K., \& Pekor, Z. (2018). Out of the education desert: How limited local college options are associated with inequity in postsecondary opportunities. Social Sciences, 7(9), 165. http://dx.doi.org/10.3390/socsci7090165

McKenzie, L., \& Baldassar, L. (2017). Missing friendships: Understanding the absent relationships of local and international students at an Australian university. Higher Education, 74(4), 701-715. https://doi.org/10.1007/s10734-016-0073-1

Nizzi, M-C.A. (2018). Assessing the sense of self [Doctoral dissertation, Harvard University Graduate School of Arts and Sciences]. https://dash.harvard.edu/handle/1/37368958

Ovink, S., Kalogrides, D., Nanney, M., \& Delaney, P. (2018). College match and undermatch: Assessing student preferences, college proximity, and inequality in post-college outcomes. Research in Higher Education, 59(5), 553-590. http://dx.doi.org/10.1007/s11162-017-9482-y

Patiniotis, J., \& Holdsworth, C. (2005). 'Seize that chance!' Leaving home and transitions to higher education. Journal of Youth Studies, 8(1), 81-95. http://dx.doi.org/10.1080/13676260500063710

Picton, F., \& Banfield, G. (2019). Using Bourdieu to understand the pathways to belonging that are forged by young students of refugee experience in an Australian mainstream school. In S. Habib, S. \& R.M. Ward (Eds.), Identities, youth and belonging: International perspectives (pp. 105-121). Palgrave Macmillan.

Posselt, J. R., Jaquette, O., Bielby, R., \& Bastedo, M. N. (2012). Access without equity: Longitudinal analyses of institutional stratification by race and ethnicity, 1972-2004. American Educational Research Journal, 49(6), 1074-1111. http://dx.doi.org/10.3102/0002831212439456 
Pretorius, L., \& Macaulay, L. (2021). Notions of human capital and academic identity in the PhD: Narratives of the disempowered. The Journal of Higher Education, 92(4), 623-647. http://dx.doi.org/10.1080/00221546.2020.1854605

Reay, D. (2002). Shaun's story: troubling discourses of white working-class masculinities. Gender and Education, 14(3), 221-234. https://doi.org/10.1080/0954025022000010695

Reay, D., Crozier, G., \& Clayton, J. (2009). 'Strangers in Paradise'? Working-class students in elite universities. Sociology, 43(6), 1103-1121. https://doi.org/10.1177/0038038509345700

Skinner, B. T. (2019). Choosing college in the 2000s: An updated analysis using the conditional logistic choice model. Research in Higher Education, 60(2), 153-183. http://dx.doi.org/10.1007/s11162-018-9507-1

Turley, R. N. L. (2009). College proximity: Mapping access to opportunity. Sociology of Education, 82(2), $126-146$. http://dx.doi.org/10.1177/003804070908200202

Ward, M. R. M. (2019). (Un)Belonging in higher education: Negotiating working-class masculinities within and beyond the university campus. In S. Habib, S. \& R.M. Ward (Eds.), Identities, youth and belonging: International perspectives (pp. 159-176). Palgrave Macmillan.

Yuval-Davis, N. (2006). Belonging and the politics of belonging. Patterns of Prejudice, 40(3), 197-214. https://doi.org/10.1080/00313220600769331

Yuval-Davis, N. (2010). Theorizing identity: Beyond the "us" and "them" dichotomy. Patterns of Prejudice, 44(3), 261280. https://doi-org.ezproxy.ups.edu:2443/10.1080/0031322X.2010.489736

Please cite this article as:

Johnson, L., \& Wiese, N. (2022). Local students at university: Narrative descriptions of lived experiences. Student Success, 13(1), 4153. https://doi.org/10.5204/ssj.2000

This article has been peer reviewed and accepted for publication in Student Success. Please see the Editorial Policies under the 'About' section of the Journal website for further information.

Student Success: A journal exploring the experiences of students in tertiary education.

(c) (1) Except where otherwise noted, content in this journal is licensed under a Creative Commons Attribution 4.0 International Licence. As an open access journal, articles are free to use with proper attribution. ISSN: 2205-0795 